\title{
Proposing an ISO/IEC 15504-2 Compliant Method for Process Capability/Maturity Models Customization
}

\author{
Jean Carlo Rossa Hauck ${ }^{1,2}$, Christiane Gresse von Wangenheim ${ }^{3}$, \\ Fergal Mc Caffery ${ }^{2}$, and Luigi Buglione ${ }^{4}$ \\ ${ }^{1}$ Graduate Program in Knowledge Engineering and Management - Federal University of Santa \\ Catarina - Brazil \\ ${ }^{2}$ Regulated Software Research Group \& Lero - Dundalk Institute of Technology - Ireland \\ ${ }^{3}$ Graduate Program in Computer Science (PPGCC) - Federal University of Santa \\ Catarina - Brazil \\ ${ }^{4}$ ETS/Engineering.IT - Rome - Italy \\ \{jeanhauck, gresse\}@gmail.com, \\ fergal.mccaffery@dkit.ie, luigi.buglionedeng.it
}

\begin{abstract}
The customization of software process capability/maturity models (SPCMMs) to specific domains/sectors or development methodologies represents one of the most discussed and applied trends in ICT organizations. Nonetheless, little research appears to have been performed on how theoretically sound and widely accepted SPCMMs should be developed to high quality. The aim of this paper is therefore to elicit the state-of-the-art regarding the processes adopted to develop such models and to propose a systematic approach to support the customization of SPCMMs. Such an approach is developed based on ISO/IEEE standard development processes integrating Knowledge Engineering techniques and experiences about how such models are currently developed in practice. Initial feedback from an expert panel indicates the usefulness and adequacy of the proposed method.
\end{abstract}

Keywords: Maturity Models, Standards, Knowledge Engineering, SPCMM, ISO/IEC 15504.

\section{Introduction}

Various Software Process Capability/Maturity Models (SPCMMs [1]) have been developed by the software engineering community, such as, CMMI-DEV [2] and ISO/IEC 15504 [3], and their use for software process improvement and assessment is well established in practice. These generic models have been customized to specific contexts [4] because diverse software development domains have specific process quality needs that should be addressed. Regulated software development domains have specific standards, such as in health care, which must be covered by the software development process in order to provide the necessary alignment to these domainspecific standards. Consequently, there is a current trend to the development of customizations of those generic process models for specific domains, such as SPICE4SPACE [5], OOSPICE [6] Automotive SPICE [7], etc. Despite this trend, most of the SPCMMs customization initiatives do not adopt a systematic approach for 
the customization of those generic standards and models [8]. Furthermore, literature detailing how SPCMMs are developed / evolved / adapted is also extremely rare [9]. Standardization organizations, like ISO or IEEE, define high-level generic processes for developing and publishing standards. However, they do not describe how to customize existing models or provide detailed technical support for the specific development of SPCMMs. The contribution of this paper is the proposal of a method for customization of SPCMMs, based on an analysis of how existing customizations have been performed, integrating standard development procedures from a Knowledge Engineering viewpoint and aligned to the requirements of ISO/IEC 15504-2 for Process Reference Models (PRM) and Process Assessment Models (PAM).

In section 2, the requirements for SPCMMs are presented. Section 3 presents methods for SPCMMs development. In section 4, the method is proposed, and section 5 presents the first results from its pilot application. Conclusions are presented in section 6 .

\section{Requirements for SPCMMs}

Different sets of requirements have been proposed for models expressing the capacity and/or maturity of processes. Becker et al. [10] propose seven criteria including: (i) comparison with existing models, (ii) iterative development, (iii) model evaluation, (iv) multi-methodological procedure, (v) identification of the relevance of problem, (vi) problem definition, (vii) published results and (viii) scientific documentation; based on the guidelines for design science. According to Matook \& Indulska [9], reference models for software process quality must meet the following requirements: generality, flexibility, completeness, usability and comprehensibility.

Regarding their structure, generally speaking, software process capability maturity models (SPCMMs), have different characteristics. Lahrmann \& Marx [11] propose a basic rationale of the structural characteristics of this type of model, as shown in Table 1.

Table 1. SPCMMs characteristics [11]

\begin{tabular}{l|l|l|l}
\hline \multicolumn{1}{c|}{ Criteria } & \multicolumn{3}{|c}{ Characteristics } \\
\hline Dimensions & One-dimensional & Multidimensional & Hierarchic \\
\hline Representation & Continuous & Staged \\
\hline Audience & Unique & Multiple \\
\hline $\begin{array}{l}\text { Assessment } \\
\text { approach }\end{array}$ & Qualitative & Quantitative \\
\hline
\end{tabular}

The requirement that characterizes the structure of software process standards and reference models (to enable classification as SPCMMs) is the fact that they have at least two dimensions: the process and dimension of capability/maturity dimension.

In a more specific way than these generic requirements, the ISO/IEC 15504-2 standard [3] establishes specific requirements for the development dimensions of the process (PRM - Process Reference Model) and capacity (PAM - Process Assessment Model) of SPCMMs, which can be summarized as follows: 
PRM

- R1 - Declaration of the specific domain and community of interest, including aspects of consensus achievement;

- $\quad \mathbf{R 2}$ - Description of processes including: unique title, purpose and outcomes;

- $\mathbf{R 3}$ - Presentation of the existent relationships between processes;

PAM

- $\quad$ R4 - Statement of scope and coverage of the model;

- $\quad \mathbf{R 5}$ - Indication of the capability levels selected from a measurement framework for the processes, starting at level 1 ;

- $\quad$ R6 - Mapping for the selected processes of the chosen PRM(s) ;

- $\quad$ R7 - Details of performance indicators of the processes, mapped to the purposes and outcomes of selected the processes of PRM(s);

- $\quad \mathbf{R 8}$ - Detailed process attributes of measurement framework;

- $\quad$ R9 - Objective evidence that the requirements are fulfilled.

The next section attempts to identify approaches that can possibly meet the existing proposed requirements for a SPCMM.

\section{Existing Methods for SPCMMs Customization}

This section presents three perspectives in an attempt to establish an overview of the development and customization of SPCMMs: proposals for approaches that support this type of development, process of standards development and main steps and techniques used in practice.

\subsection{Existing Methods for the Development of Capability/Maturity Models}

Although diverse software process capability/maturity model customizations have already taken place [8], research on how to perform such customizations in a systematic way is sparse. One of the few works in such direction was proposed by de Bruin et al. [14], introducing a six-step sequence for the development of Maturity Assessment Models. Although their work considers specific domain needs, it does not address in detail the customization of domain-specific best practices from generic models.

Mettler [15] performs a deeper analysis on the fundamentals of process maturity models, putting the main phases described in [14] under a design science research perspective. In this context, the phases are compared to a model user perspective of the maturity models, indicating a need for more formal methods and studies. Maier, Moultie \& Clarkson [16] define a guide for development of Maturity Grids that consists of tools to assess the required abilities of an organization to deliver a product or a service. The purpose of the guide covers a wider range of models, not focusing on SPCMMs.

Salviano et al. proposed the generic framework PRO2PI [17] for the development of process capability/maturity models, based on the authors' previous experiences of developing diverse models with a 7-step process. However, no details are provided in relation to the research activities and techniques that would be required to provide support for the customization of SPCMMs. Matook and Indulska [9] proposed a QFD-based approach for reference modeling incorporating the voice-of-the-referencemodel users, presenting a measure for the quality of such models. Becker et al. [10] 
also proposed a general process for the development of Maturity Models that aim to cover a set of defined requirements. However, the work did not address the question of the evolution of the model after its publication.

As it can be seen, from the few existing approaches for developing models of maturity and/or process capability, none of them is specifically targeted to meeting the requirements of the ISO/IEC 15504-2 standard. Furthermore, they are not specifically targeted to SPCMMs customization.

\subsection{Processes for the Development of Standards}

Some SPCMMs have been developed in the form of standards, supported by some regulatory body or group of international standards [12]. Standards are, in general, developed according some principles [13]: (i) consensus: in the development of a standard wide range of interests are taken into account: manufacturers, vendors, users, governments, research organizations, etc; (ii) industry wide: standards must provide global solutions for industries and customers worldwide; (iii) voluntary: standardization is an activity based on voluntary involvement of all interests in the community. For instance, ISO standards are developed in a three-phase process [13]:

- Phase 1: in general, the perceived need for a new standard comes from an industry sector, which communicates this need for a national member body. This need is then evaluated and, once approved, the scope of the new standard is set, involving working groups composed of experts from different countries.

- Phase 2: this is the phase of consensus-building. After defining the scope, it begins the negotiation between group members to detail the contents of the standard.

- Phase 3: final approval and generation of draft standard is given at this phase, where it needs to receive the approval of at least two-thirds of all members of the group and $75 \%$ of those voting. After this process of ballot, the first version of the standard is published.

Since being first proposed for publication a standard goes through a series of 9 stages and 7 related sub-stages of development ${ }^{1}$, from the preliminary till the withdrawal stage.

\subsection{Development of SPCMMs in Practice}

In order to complete the elicitation of the state-of-the-art in this context through the analysis of how SPCMMs are developed, a systematic literature review (SLR) was performed [12]. This review was performed to systematically investigate and synthesize the existing literature relating to the subject of software process capability/maturity models (SPCMMs), focusing on this research question: How are software process capability/maturity models created? Details on the SLR can be found in the Web Appendix of [12].

\footnotetext{
${ }^{1}$ www.iso.org/iso/standards_development/processes_and_procedures/ stages_description/stages_table.htm
} 
As a result of the SLR, 52 software process capability/maturity models were identified. Besides the evolution of new versions of existing models (such as, the evolution of the CMM/CMMI framework), there exists a clear trend toward the specialization of models to specific domains. Currently, a large variety of specific models exist for diverse domains, including, for example, small and medium enterprises, security engineering, knowledge management, automotive systems, XP (eXtreme Programming), etc ${ }^{2}$.

Furthermore, it was observed that these models are developed using diverse approaches. Some models, typically the ones published as standards, have been developed by following a high-level process defined by the standardization organization. These processes involve the standards community in different stages and with varying degrees of participation [13]. However, in general, it was surprising to find very little information on how SPCMMs are currently developed. Only $21 \%$ of the papers found in the SLR [12] presented detailed information on the model development, $27 \%$ contained superficial model development information and 52\% did not provide any substantial information on this aspect. The activities and techniques discovered in the detailed papers of the SLR were used within the method presented in section 4.

\subsection{Discussion}

The SLR demonstrated that a large variety of software process capability/maturity models have been developed and customized. However, in general there appears to be a lack of methodological support for the development and customization of such models. Therefore, in order to assist with the development and customization of models representing collections of best practices within a specific domain the processes used to develop and customize these models should be better understood and clearly presented. Access to standard processes for the development of such models could greatly assist the systematic development of such models and enable such models to be validated.

\section{A Proposal for a Method for the Customization of SPCMMs}

In order to promote the alignment of the customization of SPCMMs to the ISO/IEC 15504-2 requirements and to increase their quality, as well as their adoption rate in practice, a KE-based approach presented in this section was developed. The approach is based on an analysis of four elements: (i) standard development procedures; (ii) existing methods for the development of maturity models/grids; (iii) the way such customizations are currently performed; and (iv) KE techniques. From a KE viewpoint, the customization of such models relates to knowledge acquisition, collecting best practices of a specific domain by customizing generic SPCMMs to domain-specific models. A generic life cycle for KE includes [30]: (i) knowledge identification; (ii) knowledge specification and (iii) knowledge refinement. Currently, there exist several methodologies, frameworks and approaches that provide detailed support for the KE development life cycles, such as e.g., CommonKADS [31]. Furthermore, the usage and evolution of knowledge models is typically not covered

\footnotetext{
${ }^{2}$ Another list - regularly updated is available at this webpage: www.semq.eu/leng/proimpsw.htm\#quinto
} 
by SPCMMs developed to date [12]. In addition, KE techniques have so far, not yet been applied for the customization of generic SPCMMs knowledge to specific domains. The proposed method is structured in five phases:

- Phase 1 - Knowledge Identification: The main objective of phase 1 is to achieve familiarization with the target domain and a characterization of the context for which the SPCMM will be customized;

- Phase 2 - Knowledge Specification: During this central phase, a first version of the customized model is developed;

- Phase 3 - Knowledge Refinement: Within this phase, the draft model is validated, balloted and refined to develop a model approved by a majority of respective community;

- Phase 4 - Knowledge Usage: After its publication, the model is put into use and results of its usage are collected and analyzed;

- Phase 5 - Knowledge Evolution: It is necessary to provide methodological support for the continuous evolution of the model once the model has been implemented in the target domain.

Table 2. Techniques used in each method phase

\begin{tabular}{|l|l|}
\hline \multicolumn{1}{|c|}{ Method Phase } & \multicolumn{1}{|c|}{ Basic Technique(s) } \\
\hline 1. Knowledge Identification & Ontology Development [32] [33] [34] \\
& Glossary Development [35] [36] \\
& Literature Review [37] [38] [39] \\
& Systematic Literature Review [40] \\
& Goal Question Metric [41] [42] \\
& Expert Selecting [43] [44] [45] \\
& Delphi [43] [44] [45] \\
& Focus Groups [46] [47] \\
\hline 2. Knowledge Specification & Delphi [43] [44] [45] \\
& Perspective-Based Reading [59] [60] [61] \\
& Checklist-based Reading [62][63] \\
& Semantic Mapping [20] [21] [22] [23] [24] \\
& Domain quality requirements elicitation [53] [54] [55] \\
& Focus groups [46] [47] \\
& Structured Interview [31] \\
& Nominal group [56] [57] \\
& Software Process Quality Function Deployment [54] [53] [58] \\
& Process Selection [34] \\
\hline 3. Knowledge Refinement & Expert Selecting [43] [44] [45] \\
& Delphi [43] [44] [45] \\
\hline 5. Knowledge Evolution & Guidelines of Modeling [35] [36] \\
& Behavior Engineering [64] [65] [66] \\
& Interrater Agreement [67] \\
& Checklist-based Reading [62] [63] \\
\hline & Goal Question Metric [41] [42] \\
& Practical Software and Systems Measurement [68] [69] [70] \\
\hline & \\
\hline &
\end{tabular}


Each phase is composed by a set of activities that are not necessarily sequentially executed using different techniques identified as relevant both from literature and from real developing SPCMMs experiences. The activities of the various phases of the method are aligned standard 15504-2 [3], providing coverage to the requirements for PRM and PAM (see Annex 1). Table 2 shows the stages and techniques used in the method, including key references for each technique.

A detailed technical report describing the proposed method is available in [73].

\section{First Results and Discussion}

The proposed method for SPCMM customization has been developed in parallel with the customization of a SPCMM for the Software as a Service (SaaS) domain [74] and Medi SPICE [75]. So it has been applied as an Exploratory Case Study. Exploratory Case Study is a short case study, undertaken as a first step before a larger investigation. Its function is to develop the evaluation questions, measures, design and analytical strategy for a possible larger study. It is particularly useful when there is some considerable uncertainty about processes, goals and results are achieved due to the embryonic state of research [76]. Thus, for this evaluation, an exploratory case study was defined as the study design.

\subsection{A Model for Software as a Service (SaaS) Domain}

SaaS is a software solution offered as a service and is developed using SOA. As the SaaS scenario requires specific quality needs, such as, security, availability and service continuation, due to its characteristics of distributed software products as services, a customization of SPCMMs has been done. The SaaS SPCMM [74] has been developed by a group of researchers at the UFSC - Federal University of Santa Catarin (Brazil), involving experts from both the SaaS and SPI domains. The model was developed through adopting phases 1 to 3 of this method. To date, phases 4 and 5 have still not been performed.

During the development, the SaaS domain was characterized and the specialists were identified. Generic SPCMMs were also analyzed and identified as a basis for the customized model. SaaS experts were interviewed in order to analyze quality and performance needs. The results were validated in a second step through a survey. Then, SPI experts identified relevant processes and basic practices with respect to the identified quality and performance needs by mapping them. The result was a draft version of the process model.

\subsection{Medi SPICE}

In this second exploratory case study the method was applied during the development of the Medi SPICE ${ }^{3}$ Process Reference Model (PRM). Medi SPICE is an international project involving the Regulated Software Research Group in Dundalk Institute of Technology, the SPICE User Group (developers of ISO/IEC 15504 and related software process domain models), representatives from international medical

\footnotetext{
${ }^{3}$ http://medispice.ning.com
} 
device industry and representatives from the international standards community with the aim to develop a SPCMM containing software engineering best practices for the development and maintenance of medical device software [77].

Software development for medical devices has several characteristics that differentiate it from software development in other areas, especially as in order to market a medical device it is first essential to gain regulatory approval for the device within the particular region in which the device will be marketed. Due to these factors the software development activity in this area is heavily regulated by various bodies, through standards such as: AAMI / IEC 62304, FDA and European guidelines, ISO 14971, IEC 60601-1-4, ISO 13485, etc. Therefore, due to both the growth of software within the medical device industry and the revised definition of a medical device within the Medical device directive [78] there is now real need for Medi SPICE to assist software development organizations to put regulatory compliant software processes in place within the medical device industry.

The method was applied in the development of the Medi SPICE PRM during the period of January to December 2010. During this period phases 1 to 3 were also performed.

\subsection{Observed Results}

These experiences allowed us to identify strengths and weaknesses of initial versions of the proposed method in practice. One of its strengths is the involvement of specialists, although we also identified that in order to stimulate a wide adoption of the model, a much stronger involvement of the community is also required. Other strength is the methodological support which typically, for standard developments, is not available. We also observed several improvement opportunities:

- Support for a systematic mapping and harmonization of existing models;

- Better methodological support for consensus building among community representatives throughout the models development and not just elicitation of their knowledge;

- More systematic and formal support for the validation of the models.

- Integration of data-based input to the models if available in the specific domain in order to complete the expert's knowledge.

In addition, we are currently performing a systematic validation of the method through an expert panel. The main objective of this validation is to evaluate the method's ability to produce valid models (presenting generality, flexibility, completeness, usability and comprehensibility) and models aligned to the requirements of ISO/IEC 15504-2, from the point of view of specialists in maturity models in the context of an Expert Panel.

Experts discovered in the SLR [12] were invited to evaluate the method. To date, we have obtained responses from 12 SPI experts that have participated in the development of 17 different SPCMMs, with 55\% having more than 10 years of experience in SPI.

A first preliminary analysis of the responses indicates that the method, in the opinion of $72 \%$ of the experts, has the potential ability to produce valid models 
(presenting generality, flexibility, completeness, usability and comprehensibility). We also observed that $82 \%$ of the respondents felt that the method provides enough support for developing SPCMMs and adequately represents what is necessary to customize a SPCMM. All respondents felt that usage of the method could produce models aligned to the requirements of the ISO/IEC 15504-2 (for PRM and PAM).

\section{Conclusions}

In this paper, we outlined an approach for SPCMM customization by integrating a Knowledge Engineering (KE) perspective, customization experiences from literature and standard development processes. A first application of the proposed approach for the customization of a SaaS SPCMM provided a first indication that the approach can be useful for the customization of such models as well as enabling the identification strengths and weaknesses. Based on the feedback, we are currently evolving and refining the proposed approach as well as continuing its application in parallel for the customization of SPCMMs, such as, for medical devices as well as digital convergence.

\section{Acknowledgements}

This work was supported by the CNPq (Conselho Nacional de Desenvolvimento Científico e Tecnológico) and CAPES (Coordenação de Aperfeiçoamento de Pessoal de Nível Superior), both entities of the Brazilian government focused on scientific and technological development. The Medi SPICE part of this research is supported by the Science Foundation Ireland (SFI) Stokes Lectureship Programme, grant number 07/SK/I1299, the SFI Principal Investigator Programme, grant number 08/IN.1/I2030 and supported in part by Lero - the Irish Software Engineering Research Centre (http://www.lero.ie).

\section{References}

[1] Salviano, C.F., Figueiredo, A.M.C.M.: Unified Basic Concepts for Process Capability Models. In: 20th Int Conf on Sw. Eng. and Knowledge Eng (SEKE 2008), San Francisco, USA, pp. 173-178 (2008),

http://pro2pi.wdfiles.com/local-files/publicacoes-sobre-ametodologia/SalvianoandFigueiredo-2008-PRO2PI-SEKEarticle.pdf

[2] CMMI Product Team. CMMI for Development (CMMI-DEV), Version 1.3, Technical Report, CMU/SEI-2010-TR-033, Software Engineering Institute (2010), http: / / www. sei.cmu.edu/cmmi/tools / cmmiv1-3/

[3] International Organization for Standardization (ISO) / International Electrotechnical Commission (IEC) ISO/IEC, ISO/IEC 15504: Information Technology Process Assessment - Part 1 to 5, International Organization for Standardization (ISO) / International Electrotechnical Commission (IEC), ISO/IEC International Standard (2005)

[4] Beecham, S., Hall, T., Rainer, A.: Building a Requirements Process Improvement Model, Faculty of Engineering and Information Sciences, University of Hertfordshire, Hertfordshire, Technical Report 378 (2003), 
https: / /uhra.herts.ac.uk/dspace/bitstream/2299/986/1/S67.pdf

[5] Cass, A., Volcker, C.: SPICE for SPACE: A method of Process Assessment for Space Projects. In: SPICE 2000 Conference (2000)

[6] Torgersson, J., Dorling, A.: Assessing CBD - What's the Difference? In: 28th Euromicro Conference, Dortmund, Germany, pp. 332-341 (2002)

[7] Automotive SIG. The SPICE User Group Automotive Special Interest Group, Automotive SPICE Process Reference Model (2010), http: / / www . automotivespice.com

[8] Wangenheim, C.G., Hauck, J.C.R., Salviano, C.F., Wangenheim, A.: Systematic Literature Review of Software Process Capability/Maturity Models. In: Proceedings of the 10th SPICE Conference 2010, Pisa, Italy (2010)

[9] Matook, S., Indulska: Improving the quality of process reference models: A quality function deployment-based approach. Decision Support Systems 47, 60-71 (2009), http: / / espace.library.uq.edu.au/eserv/UQ:161303/Matook_Indul ska_DDS_2009.pdf

[10] Becker, J., Knackstedt, R., Pöppelbuß, J.: Developing Maturity Models for IT Management - A Procedure Model and its Application. Business \& Information Systems Engineering 1(3), 213-222 (2009),

http: / /www.bise-journal.org/index.php, do=show/site=wi / sid=16424296734d2251f9628a7985168360/alloc=17/id=2429

[11] Lahrmann, G., Marx, F.: Systematization of maturity model extensions. In: Winter, R., Zhao, J.L., Aier, S. (eds.) DESRIST 2010. LNCS, vol. 6105, pp. 522-525. Springer, Heidelberg (2010)

[12] Wangenheim, C.G., Hauck, J.C.R., Mccaffery, F., Wangenheim, A.: Creating Software Process Capability/ Maturity Models. IEEE Software 27(4) (2010)

[13] International Organization for Standardization (ISO). How are Standards Developed, http://www.iso.org/iso/standards_development/processes_and_p rocedures/how_are_standards_developed.htm

[14] de Bruin, T., Rosemann, M., Freeze, R., Kulkarmi, U.: Understanding the Main Phases of Developing a Maturity Assessment Model. In: 16th Australasian Conference on Information Systems, Sydney (2005),

http: / / www. followscience.com/library_uploads/ceba558bded879c cc0b45cd2c657e870/123/understanding_the_main_phases_of_devel oping_a_maturity_assessment_model.pōf

[15] Mettler, T.: A Design Science Research Perspective on Maturity Models in Information Systems, Universität St. Gallen, St. Gallen, Switzerland, Technical Report BE IWI/HNE/03 (2009), http://www.alexandria.unisg.ch/export/DL/67708.pdf

[16] Maier, A.M., Moultrie, J., Clarkson, P.J.: Developing maturity grids for assessing organisational capabilities: Practitioner guidance. In: 4th International Conference on Management Consulting, Academy of Management (MCD 2009), pp. 11-13 (2009), http://www.iff.ac.at/oe/full_papers/Maier\%20Anja\%20M._Moultr ie\%20James_Clarkson\%20P. $\% 20 J o h n . p d f$

[17] Salviano, C.F., Zoucas, A., Silva, J.V.L., Alves, A.M., von Wangenheim, C.G., Thiry, M.: A Method Framework for Engineering Process Capability Models. In: 16th European Systems and Software Process Improvement and Innovation, Alcala, Spain, pp. 6.25-6.36 (2009)

[18] Lee, J.-H., Lee, D.H., Kang, S.: An overview of the business process maturity model (BPMM). In: Chang, K.C.-C., Wang, W., Chen, L., Ellis, C.A., Hsu, C.-H., Tsoi, A.C., Wang, H. (eds.) APWeb/WAIM 2007. LNCS, vol. 4537, pp. 384-395. Springer, Heidelberg (2007)

[19] Beecham, S., et al.: Defining a Requirements Process Improvement Model. Software Quality Journal 13(3), 247-279 (2005) 
[20] Beecham, S., et al.: Using an Expert Panel to Validate a Requirements Process Improvement Model. Journal of Systems and Software 76(3), 251-275 (2005)

[21] Paulk, M.C., et al.:Capability Maturity Model for Software, Version 1.1, Technical Report, CMU/SEI-93-TR-024, Software Engineering Institute (February 1993), http: / /www.sei.cmu.edu/reports/93tr024.pdf

[22] Cass, A., et al.: SPiCE in Action - Experiences in Tailoring and Extension. In: 28th Euromicro Conference, Dortmund, Germany (2002)

[23] Bovee, M., et al.: A Framework for Assessing the Use of Third-Party Software Quality Assurance Standards to Meet FDA Medical Device Software Process Control Guidelines. IEEE Transactions on Engineering Management 48(4), 465-478 (2001)

[24] Niazi, M., et al.: A Maturity Model for the Implementation of Software Process Improvement: An Empirical Study. Journal of Systems and Software 74(2), 155-172 (2005)

[25] April, A., Coallier, F.: Trillium: A Model for the Assessment of Telecom Software System Development and Maintenance Capability. In: 2nd IEEE Software Engineering Standards Symposium, Montreal, Canada (1995)

[26] Burnstein, I., et al.: Developing a Testing Maturity Model, Part II, Crosstalk (September 1996)

[27] TMMI Foundation, TMMI - Test Maturity Model Integration, http: / /www. tmmi foundation.org/html/tmmiorg.html

[28] Kyung-A, Y., Seung-Hun, P., Doo-Hwan, B., Hoon-Seon, C., Jae-Cheon, J.: A Framework for the V\&V Capability Assessment Focused on the Safety-Criticality. In: 13th IEEE International Workshop on Software Technology and Engineering Practice, Budapest, Hungary, pp. 17-24 (2005),

http: / /spic.kaist.ac. kr/ selab/html/Publication/IntJournal / A $\% 20$ framework $\% 20$ for $\% 20$ the $\% 20 V \& V \% 20$ capability $\% 20$ assessment $\% 20 f$ ocused\%20on\%20the\%20safety-criticality.pdf

[29] McCaffery, F., Pikkarinan, M., Richardson, I.: AHAA - Agile, Hybrid Assessment Method for Automotive, Safety Critical SMEs. In: Proc: International Conference on Software Engineering (ICSE 2008), Leipzig, Germany (2008)

[30] Schreiber, A.T., Wielinga, B.J.: Knowledge Model Construction. In: 11th Workshop on Knowledge Acquisition, Modeling and Management, Voyager Inn, Banff, Alberta, Canada (1998), http://ksi.cpsc.ucalgary.ca/KAW/KAW98/schreiber/

[31] Schreiber, G., Akkermans, H., Anjewierden, A., De Hoog, R., Shadbolt, N., Van De Velde, W., Wielinga, B.: Knowledge Engineering and Management - The CommonKADS Methodology. The MIT Press, Cambridge (2000) ISBN 978-0262193009

[32] Gruber, T.R.: Toward Principles for the Design of Ontologies Used for Knowledge Sharing, Technical Report, KSL 93-04, Knowledge Systems Laboratory, Stanford University, Palo Alto, CA, USA (1993), http: / / wwwksl. stanford.edu/knowledge-sharing/papers /

[33] Noy, N., McGuinness, D.L.: Ontology Development 101: A Guide to Creating Your First Ontology. Stanford Knowledge Systems Laboratory Technical Report KSL-01-05 and Stanford Medical Informatics Technical Report SMI-2001-0880 (March 2001), http: / / www.ksl.stanford.edu/KSL_Abstracts/KSL-01-05.html

[34] Hsieh, S.H., Hsien-Tang, L., Nai-Wen, C., Kuang-Wu, C., Ken-Yu, L.: Enabling the development of base domain ontology through extraction of knowledge from engineering domain handbooks. In: Advanced Engineering Informatics (2010) (in press), http://dx.doi.org/10.1016/j.aei.2010.08.004

[35] Government of South Australia. Developing a Thesaurus Guideline Version 1.2, State Records of South Australia (2002),

http: //www.archives.sa.govol.au/files/management_guidelines_ developingthesaurus.pdf 
[36] Sikorski, M.: A Framework for developing the on-line HCI Glossary: Technical Report, Technical University of Gdansk (2002), http://www.org.id.tue.nl/IFIPWG13.1/HCIglossary. PDF

[37] Mongan-Rallis, H.: Guidelines for writing a literature review, http://www. duluth. umn. edu/ hrallis/guides/researching/litrev iew.html

[38] Galvan, J.: Writing literature reviews: a guide for students of the behavioral sciences, 3rd edn. Pyrczak Publishing, Glendale (2006) ISBN 978-1884585661

[39] Cronin, P., Coughlan, M., Frances, R.: Undertaking a literature review: a step-by-step approach. British Journal of Nursing 17(1) (2008), http: //lancashirecare.files.wordpress.com/2008/03/2008undertaking-a-literature-review-a-step-by-step-approach.pdf

[40] Kitchenham, B.A.: Guidelines for performing Systematic Literature Reviews in Software Engineering. Version 2.3 Technical report, University of Durham, Keele, UK (2007), http://www.elsevier.com/framework_products/promis_misc/infso f-systematic\%20reviews.pdf

[41] Basili, V.R., Caldiera, G., Rombach, H.D.: The Goal Question Metric Approach, 2nd edn. Encyclopedia of Software Engineering. John Wiley \& Sons, Chichester (1994), http://www.cs. umd. edu/ basili/publications/technical/T89.pdf

[42] Wangenheim, C.G., et al.: Software Measurement for Small and Medium Enterprises - A Brazilian-German view on extending the GQM method. In: 7th International Conference on Empirical Assessment ion Software Engineering, Keele, UK (2003)

[43] Okoli, C., Pawlowski, S.D.: The Delphi method as a research tool: an example, design considerations and applications. Inf. Manage (2004), http://chitu.okoli.org/images/stories/bios/pro/research/meth ods / OkoliPawlowski2004.pdf

[44] de Bruin, T., Rosemann, M.: Using the Delphi Technique to Identify BPM Capability Areas. In: 18th Australasian Conference on Information Systems, vol. 42, pp. 15-29 (2007), http: / /www.acis2007.usq. edu.au/assets / papers / 106.pdf

[45] Powell, C.: The Delphi technique: myths and realities. Journal of Advanced Nursing 41(4), 376-382 (2003),

http://rachel.org/files/document/The_Delphi_Technique_Myths_ and_Realities.pdf

[46] Kontio, J., Lehtola, L., Bragge, J.: Using the Focus Group Method in Software Engineering: Obtaining Practitioner and User Experiences. In: International Symposium on Empirical Software Engineering, pp. 271-280 (2004), http://www.sbl.tkk.fi/jkontio/Papers / FocusGroup_ISESE_web.pdf

[47] Free Management Library. Basics of Conducting Focus Groups, http: / / managementhelp.org/evaluatn/focusgrp.htm

[48] Mutafelija, B., Stromberg, H.: Process Improvement with CMMI v1.2 and ISO Standards. Auerbach, Boca Raton (2008) ISBN 978-1420052831

[49] Thiry, M., Zoucas, A., Tristão, L.: Mapeando Modelos de Capacidade de Processo no Contexto de Avaliações Integradas de Processo de Software. In: II Workshop on Advanced Software Engineering, pp. 35-42 (2009)

[50] Wangenheim, C.G., Thiry, M.: Analyzing the Integration of ISO/IEC 15504 and CMMISE/SW, Universidade do Vale do Itajaí, São José, Technical Report LQPS001.05E (2005)

[51] Wangenheim, C.G., et al.: Best practice fusion of CMMI-DEV v1.2 (PP, PMC, SAM) and PMBOK 2008. Information and Software Technology 52(7), 749-757 (2010)

[52] Beel, J., Gipp, B.: Link Analysis in Mind Maps: A New Approach To Determine Document Relatedness. In: Proceedings of the 4th International Conference on Ubiquitous Information Management and Communication (ICUIMC 2010). ACM, New York (2010),

http: / /www.sciplore.org/publications / 2010 -LAMM-preprint.pdf 
[53] Cancian, M.H., Hauck, J.C.R., von Wangenheim, C.G., Rabelo, R.J.: Discovering software process and product quality criteria in software as a service. In: Ali Babar, M., Vierimaa, M., Oivo, M. (eds.) PROFES 2010. LNCS, vol. 6156, pp. 234-247. Springer, Heidelberg (2010), http: //www.das.ufsc.br/ maiara/files/profes_maiara.pdf

[54] Richardson, I.: SPI Models: What Characteristics are Required for Small Software Development Companies. Software Quality Journal, 101-114 (2002) http://portal.acm.org/citation. cfm?id=650270

[55] Beecham, S., Hall, T., Rainer, A.: Defining a Requirements Process Improvement Model. Software Quality Journal 13(3), 247-279 (2005)

[56] Sample, J.A.: Nominal Group Technique: An Alternative to Brainstorming. Journal of Extension 22(2) (1984), http: / / www. joe.org/joe/1984march/iw2 . php

[57] CDC. Gaining Consensus Among Stakeholders Through the Nominal Group Technique. Evaluation Briefs (7) (2006), http: / /www.cdc.gov/HealthyYouth/evaluation/pdf/brief7.pdf

[58] Matook, S., Indulska, M.: Improving the Quality of Process Reference Models: A Quality Function Deployment-Based Approach. Decision Support Systems 47 (2009), http: / / espace.library.uq.edu.au/eserv/UQ:161303/Matook_Indul ska_DDS_2009.pdf

[59] Basili, V.R., et al.: The Empirical Investigation of Perspective-Based Reading. Empirical Software Engineering, Kluwer Academic Publisher 1, 133-164 (1996), http: / / www. cs. umd. edu/ basili/publications/journals/J63.pdf

[60] Shull, F., Rus, I., Basili, V.: How perspective-based reading can improve requirements inspections. Computer 33(7), 73-79 (2000)

[61] Robbins, B., Carver, J.: Cognitive factors in perspective-based reading (PBR): A protocol analysis study. In: 3rd International Symposium on Empirical Software Engineering and Measurement (ESEM 2009), pp. 145-155 (2009)

[62] McMeekin, D.A., et al.: Checklist Based Reading's Influence on a Developer's Understanding. In: 19th Australian Conference on Software Engineering (2008), http: / /www. computer.org/portal/web/csdl/doi/10.1109/ASWEC. 20 08.7

[63] Fagan, M.E.: Design and code inspections to reduce errors in program development. IBM Systems Journal 15(3), 182-211 (1976), http: / / www. cs. umd. edu/class / spring2 $005 / \mathrm{cmsc} 838 \mathrm{p} /$ VandV/fagan. pdf

[64] Behaviour Engineering, http: / /www. behaviorengineering.org/

[65] Dromey, R.G.: From Requirements to Design: Formalizing the Key Steps. In: 1st International Conference on Software Engineering and Formal Methods, Australia (2003)

[66] Tuffley, D., Rout, T.P.: Applying Behavior Engineering to Process Modeling. In: Proceedings of the Improving Systems and Software Engineering Conference, ISSEC (2009), http: / /www98.griffith.edu.au/dspace/handle/10072/31748

[67] Emam, K.E.: Benchmarking Kappa for Software Process Assessment Reliability Studies. Empirical Software Engineering 4(2), 113-133 (2004)

[68] Practical Software and Systems Measurement, http: / /www . psmsc.com

[69] DoD, Department of Defense \& US Army. PSM - Practical Software and System Measurement, A foundation for Objective Project Management, Version 4.0b, Department of Defense \& US Army (2003), http: / / www . psmsc . com

[70] ISO/IEC. ISO/IEC 15939:2007 Systems and software engineering - Measurement process. International Organization for Standardization (2007)

[71] CMMI Change Requests, http: / /www. sei.cmu .edu/cmmi/tools/cr/

[72] Enterprise Spice SPICE Change Request, http: / /www. enterprisespice.com/page/publication-1 
[73] Hauck, J. C. R., Wangenheim, C. G., Wangenheim, A.: A Knowledge Engineering Based Method for SPCMMs customization, Technical Report RT_GQS_0_9, INCoD Software Quality Group (2010),

http://www.inf.ufsc.br/ jeanhauck/method/RT_GQS_01_SPCMMs_De V_Method_v_0_9.pdf

[74] Cancian, M.: Process Reference Model for SaaS. Technical Report. UFSC, Florianopolis/Brazil, http: / / www.gsigma.ufsc.br/ cancian/guide/

[75] McCaffery, F., Dorling, A.: Medi SPICE Development. Software Process Maintenance and Evolution: Improvement and Practice Journal 22(4), 255-268 (2010)

[76] GAO - United States General Accounting Office. Case Study Evaluations, Technical Report GAO/PEMD-91-10.1.9. Program Evaluation and Methodology Division (1990), http: //www.gao.gov/special.pubs/10_1_9.pdf

[77] McCaffery, F., Dorling, A., Casey, V.: Medi SPICE: An Update. In: Proceedings of the 10th International SPICE Conference, Italy (2010)

[78] European Council. Council Directive 2007/47/EC (Amendment). Official Journal of The European Union, Luxembourg (2007),

http: / / eur-lex.europa.eu/LexUriServ/

LexUriServ.do?uri=OJ : L: 2007:247:0021:0055:en: PDF 


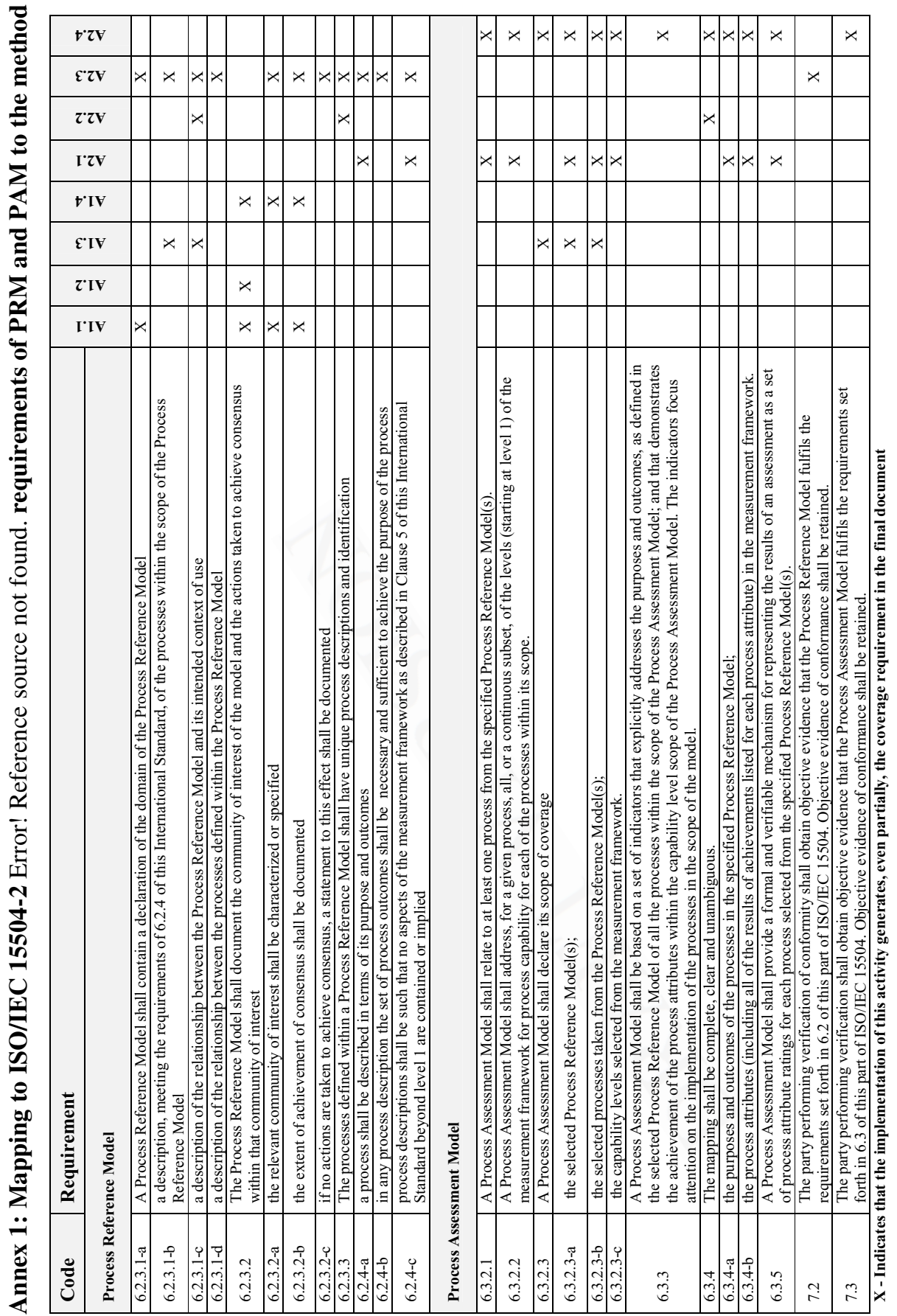

